\title{
A Standardized Method for Determining Tillering Capacity of Wheat Cultivars
}

\author{
Jordan D. Stanley ${ }^{*}$, Grant H. Mehring², Jochum J. Wiersma ${ }^{3}$, Joel K. Ransom ${ }^{4}$ \\ ${ }^{1}$ Syngenta Crop Protection, LLC, Glyndon, Minnesota, USA \\ ${ }^{2}$ WestBred, Bayer Crop Science, Fargo, North Dakota, USA \\ ${ }^{3}$ Department of Agronomy and Plant Genetics, University of Minnesota, Crookston, Minnesota, USA \\ ${ }^{4}$ Department of Plant Sciences, North Dakota State University, Fargo, North Dakota, USA \\ Email: ${ }^{*}$ rmcropdoc@gmail.com
}

How to cite this paper: Stanley, J.D., Mehring, G.H., Wiersma, J.J. and Ransom, J.K. (2020) A Standardized Method for Determining Tillering Capacity of Wheat Cultivars. American Journal of Plant Sciences, 11, 604-625.

https://doi.org/10.4236/ajps.2020.115046

Received: April 11, 2020

Accepted: May 6, 2020

Published: May 9, 2020

Copyright (c) 2020 by author(s) and Scientific Research Publishing Inc. This work is licensed under the Creative Commons Attribution International License (CC BY 4.0).

http://creativecommons.org/licenses/by/4.0/

\section{Open Access}

\begin{abstract}
Genotype and agronomic management greatly influence crop growth and grain yield in wheat (Triticum aestivum L.). To ensure sustainable production, seeding rate selection is important to maximize efficiency of every plant. Tillering can allow wheat plants to adjust growth relative to plant density and quality of growing conditions. This research sought to determine a method for assessing tillering of wheat cultivars and develop a standardized approach for characterizing cultivar tillering capacity. Nine cultivars with diverse genetic and phenotypic characteristics were seeded in 2017-2018 at Prosper, ND using various seeding techniques at differing plant spacing arrangements to evaluate tillering habit and spikes plant ${ }^{-1}$. Cultivars grown at population densities common in grower fields did not express full tillering potential. Spacedplantings of cultivars promoted cultivar expression of tillering phenotype. The SOFATT (seed only a few, and then thin) method, where average spikes plant $^{-1}$ was determined from multiple plants sampled from a cultivar grown at spaced-plantings (inter-row and intra-row spacing at $30 \pm 12 \mathrm{~cm}$ ), is recommended to properly assess tillering habits of wheat cultivars. Breeders and researchers can use results from SOFATT evaluations to determine tillering capacity rating for each cultivar based on raw or transformed z-score values for spikes plant ${ }^{-1}$.
\end{abstract}

\section{Keywords}

Tillering Capacity, Wheat Cultivar, Seeding Density, Plant Spacing, Z-Score

\section{Introduction}

Genotype is a primary determinant of yield potential in wheat (Triticum aesti- 
vum L.) cultivars [1] [2]. The actual yield attained by a wheat cultivar is greatly influenced by interactive effects from environment and agronomic management. One way that these factors can affect yield is by influencing plant growth habit and composition of yield components. For wheat grown in irrigated, intensively-managed environments, production of uniculm plants is considered ideal for yield [3]. As the majority of hard red spring wheat (HRSW) in the Northern Plains region of the U.S. is seeded in dryland environments, crop management for economic production includes using cultivars with both main stem and tillers contributing to yield. Tillering can allow plants to adjust growth relative to density of neighboring plants or quality of growing conditions [4]. Diversity among modern HRSW cultivars includes a range of genotypes differing in plant growth habit and tillering capacity. Although an extensive record of publications document efforts employed to identify quantitative trait loci (QTL) associated with tillering in wheat, no findings have been published to date identifying a specific gene associated with tillering traits [5] [6].

Agronomic management for sustainable HRSW production includes selecting a seeding rate that will maximize efficiency of production for every plant. For example, a high tillering cultivar could be seeded at a lower rate compared to a cultivar with a lower number of tillers contributing to total grain yield. When determining the seeding rate optimal for cultivar yield, it is important to consider the tillering capacity of a cultivar to avoid economic losses due to unnecessary seed costs (overseeding) or uncaptured yield (underseeding). Underseeding to promote plant tillering is likely to negatively impact yield if the plant is not prolific at tillering, though differences in reportings for percent of total grain yield contributed by tillers (range $6.7 \%$ to $46.9 \%$ ) make it difficult to determine a definitive percent [7] [8]. Additionally, underseeding a field with a low tillering cultivar can limit leaf area index, reducing the amount of radiative light intercepted $\mathrm{ha}^{-1}$, and thereby lowering production efficiency and subsequent yield at harvest [9]. Richards and Townley-Smith [10] noted that greater leaf area index proved to be a disadvantage for high tillering cultivars subjected to early drought conditions occurring prior to anthesis. When drought conditions were only present after anthesis, pre-anthesis vegetative growth was estimated to contribute $60 \%$ of total grain yield.

Though it is apparent that differences among cultivars in tillering capacity and plant leaf area influence yield, spikes plant ${ }^{-1}$ generally has a greater influence on plant yield [11]. Applying this understanding on a field scale, Holliday [12] noted yield gains observed in high tillering stands could be attributed to contributions from spikes, based on the understanding of spike photosynthetic efficiency reported by Archbold and Mukerjee [13]. Elhani et al. [14] conducted tillering experiments and concluded that a high tillering capacity provided cultivars with advantages in plant growth habit and yield components over low tillering cultivars, but only in non-stressed, irrigated environments. Hucl and Baker [15] noted that though tillers $\mathrm{m}^{-2}$ is closely associated with spikes $\mathrm{m}^{-2}(r=$ $0.84)$, spikes $\mathrm{m}^{-2}$ is a poor determinant of yield $\left(R^{2}=0.005\right)$. Considering diversity in 
tillering capacity among cultivars and production potential across environments, these findings reinforce the importance of considering cultivar tillering capacity when determining optimal seeding rates to maximize yield throughout the Northern Plains region.

Although environment can influence tillers plant ${ }^{-1}$ produced by a cultivar, it can be expected to observe similar relative responses in other cultivars across environments. Klepper et al. [16] indicated that the process of wheat plant development is unchanged across environment types, but noted that environment affects the rate at which development occurs. This can be used to explain the reporting from Friend [17] that reduced tiller numbers in mature wheat plants was not attributable to the plant's inability to form tiller buds, but rather the lack of tillers emerging from axillary buds. Though environment and agronomic factors can impact tillering, it can be expected that genotypes will not be differentially affected by these factors. Work completed by Richards [5] provides support for this statement as varying planting timing of spring-seeded wheat produced similar changes in spikes plant ${ }^{-1}$ among tillering cultivars. Evaluations of tiller numbers of cultivar seeded in various arrangements (adaptations in spacing and rectangularity) indicated arrangement had no interactive effect on cultivar tillering [18]. Carr et al. [19] found that no rank changes were observed among HRSW cultivars when evaluating tillage and seeding rate effects on tiller production. In general, these study all document cultivar responses to agronomic practices that are similar in scale across cultivars.

Numerous published findings have noted differences in tiller number in response to changes in agronomic management for row spacing, seeding rate, and planting method. However, documentation is minimal for current methods used by breeders and researchers to assess tillering characteristics of individual cultivars. Hucl and Baker [15] utilized various approaches for evaluating tillering characteristics of wheat genotypes based on spikes plant ${ }^{-1}$. One approach included single row planting and subsequent thinning to 10 plants $\mathrm{m}^{-2}$ for sampling of 5 plants to represent each genotype. Additional approaches included solid-seeded ( 2.40 million seed ha ${ }^{-1}$ ) and space-planted (est. 0.12 million seeds ha ${ }^{-1}$ ) conditions to determine spikes plant ${ }^{-1}$ for relative comparisons among genotypes. The objective of the space-planted method was to provide growing conditions with minimal competition among plants to promote plant tillering for full evaluation of genotype tillering capacity. Of the 373 genotypes originally evaluated, the genotypes with the 10 lowest, and 10 highest values for spikes plant ${ }^{-1}$ were reported as low tillering and high tillering genotypes, respectively. This study demonstrated various experimental approaches used to identify high and low tillering genotypes, based on relative rank among genotypes for spikes plant $^{-1}$. However, not all HRSW cultivars available to growers are designated as having characteristics of high tillering or low tillering. This reinforces the importance of developing a standardize system for assessing cultivar tillering habit and determining a tillering capacity rating.

Without a standardized system for assessing cultivars for tillering characteris- 
tics, there is greater uncertainty in optimal seeding rates for HRSW cultivars due to additional error associated with subjective evaluation of cultivar tillering habits. Developing a standardized method for assessing tillering capacity of genotypes provides breeding programs with a tool to readily determine this important characteristic to include in the description of new cultivars upon release.

The objectives of this research were to determine a method for assessing tillering of HRSW cultivars and develop a standardized approach for characterizing cultivar tillering capacity. Various seeding techniques were applied in differing plant spacing arrangements to evaluate tillering habit and spikes plant ${ }^{-1}$ of diverse HRSW cultivars.

\section{Materials and Methods}

\subsection{Site Description}

Three different experiments were used in this study to profile various assessment methods. All experiments were established at the agricultural research site near Prosper, ND $\left(47.003^{\circ}-97.116^{\circ}\right)$, with a soil type that is characterized as somewhat poorly drained consisting of a complex of Kindred (fine-silty, mixed, superactive, frigid Typic Endoaquolls) and Bearden (fine-silty, mixed, superactive, frigid Aeric Calciaquolls) soils with a minimal slope (0\% - 2\%). Experiment 1 was established in 2017 and 2018 (two environments). Experiment 2 and Experiment 3 were established in 2018. Sites were cropped to HRSW in the year prior. Sites received disc tillage in the fall prior, and a field cultivator in the spring, prior to planting. Agronomic management (including cultivation, fertilization, and pest management) followed North Dakota State University (NDSU) extension recommendations to ensure inputs were not an additional source of variance.

\subsection{Experimental Approach}

Experiment 1 was conducted concurrently within a small plot seeding rate experiment. Experimental units were $5.5 \mathrm{~m}^{2}$ plots in a randomized complete block design with a factorial arrangement of cultivar and seeding rate. Treatments included combinations of four seeding rates and nine HRSW cultivars (Table 1) seeded in 7 rows at $18 \mathrm{~cm}$ spacing with a Great Plains no-till drill (Kincaid Research, Haven, KS). Cultivars were selected to include a diversity of genetic backgrounds and phenotypes (Table 2). Plant counts were completed within each plot around the 2-leaf stage (Zadoks 12 to 15, [20]) by placing markers 91 $\mathrm{cm}$ apart within two of the innermost rows and counting all wheat plants between markers. At physiological maturity (Zadoks 89), all productive spikes between markers were counted and averaged over early-season plant counts in each sampling area. Values from both areas sampled were averaged to determine average spikes plant ${ }^{-1}$ for each plot. Spikes plant ${ }^{-1}$ was selected (versus spikes $\mathrm{m}^{-2}$ or stems $\mathrm{m}^{-2}$ ) to evaluate various plant spacing arrangements to determine the method most appropriate for evaluating cultivar tillering abilities. As Hucl [21] reported spacing arrangement comparisons based on spikes plant ${ }^{-1}$ were 
Table 1. Experiment 1 factors and treatments of 2017-2018 experiments at Prosper, ND.

\begin{tabular}{|c|c|}
\hline Factor & Treatment \\
\hline \multirow[t]{9}{*}{ Cultivar } & LCS Anchor \\
\hline & Lang-MN \\
\hline & Linkert \\
\hline & Prevail \\
\hline & Shelly \\
\hline & Surpass \\
\hline & SY Valda \\
\hline & ND VitPro \\
\hline & TCG Wildfire \\
\hline \multirow[t]{4}{*}{ Seeding Rate } & 1.85 million seeds $\mathrm{ha}^{-1}$ \\
\hline & 3.09 million seeds $\mathrm{ha}^{-1}$ \\
\hline & 4.32 million seeds $\mathrm{ha}^{-1}$ \\
\hline & 5.56 million seeds $\mathrm{ha}^{-1}$ \\
\hline
\end{tabular}

Table 2. Select genetic and phenotypic characteristics ${ }^{1}$ of HRSW cultivars in experiment.

\begin{tabular}{cccccccc}
\hline \multirow{2}{*}{ Cultivar } & Source & \multicolumn{2}{c}{ Plant stature $^{2}$} & Photoperiodism $^{3}$ & Height & $\begin{array}{c}\text { Straw } \\
\text { strength }\end{array}$ & Heading \\
\cline { 3 - 8 } & & Rht- $B 1$ & $R h t-D 1$ & $P p d-D 1$ & $\mathrm{~cm}$ & $(1-9)^{4}$ & DAP $^{5}$ \\
\hline LCS Anchor & Limagrain & $a$ & $b$ & $a$ & 71.9 & 5 & 58 \\
Lang-MN & UMN & $a$ & $a$ & $a$ & 82.6 & 5 & 61 \\
Linkert & UMN & $a$ & $b$ & $b$ & 72.9 & 2 & 59 \\
Prevail & SDSU & $a$ & $a$ & $a$ & 78.2 & 4 & 58 \\
Shelly & UMN & $b$ & $a$ & $b$ & 77.0 & 5 & 62 \\
Surpass & SDSU & $a$ & $a$ & $b$ & 79.8 & 7 & 56 \\
SY Valda & AgriPro & $a$ & $b$ & $b$ & 75.9 & 4 & 60 \\
ND VitPro & NDSU & $b$ & $a$ & $b$ & 80.0 & 4 & 59 \\
TCG Wildfire & 21 st Century & $b$ & $a$ & $a$ & 86.6 & 4 & 60 \\
\hline
\end{tabular}

${ }^{1}$ Data obtained from North Dakota HRSW variety trial selection guide [22]. ${ }^{2} a$ is wild-type allele, $b$ is semi-dwarf allele. ${ }^{3} a$ is insensitive allele, $b$ is sensitive allele. ${ }^{4}$ Lodging score; 1 is standing erect, 9 is lying flat. ${ }^{5} \mathrm{DAP}$, days after planting.

only slightly correlated $(r=0.33)$, the focus was on relative cultivar response across the various methods.

Space-planted methods were used in Experiment 2 and Experiment 3 to promote cultivar expression of tillering phenotype by minimizing competition among plants [15]. Experiment 2 was a randomized complete block design with four replicates. Nine HRSW cultivars were assigned as treatments. Experimental units were $5.5 \mathrm{~m}^{2}$ plots seeded with a 4-row Hege 1000 no-till planter (Hege Company, Waldenburg, Germany) with $30 \mathrm{~cm}$ spacing. A SOFATT (seed only a 
few, and then thin) method was applied by seeding at a fixed rate of 215,000 seeds $\mathrm{ha}^{-1}$ with the objective to establish wheat plants within each plot at an equidistant of $30 \mathrm{~cm}$ for both intra-row and inter-row spacing. Plots were thinned in early June to remove excess wheat plants, including any plants spaced $<18 \mathrm{~cm}$ from a neighboring plant (Figure 1). Spikes plant ${ }^{-1}$ was measured at physiological maturity (Zadoks 89) to allow plants to reach full tillering potential [22]. Intra-row spacing of plants (in meters) and mean spikes plant ${ }^{-1}$ were recorded for each plot by averaging spike counts of 8 plants sampled from each plot (Figure 2).

Experiment 3 was a randomized complete block design with 24 replicates. Nine HRSW cultivars were assigned as treatments. Experimental units were 0.09 $\mathrm{m}^{2}$ single-seed hills planted with a 4-row bubble tray hill plot planter at equidistant spacing $(30 \mathrm{~cm} \times 30 \mathrm{~cm})$. Spikes plant ${ }^{-1}$ were determined at physiological maturity for each cultivar replicate.

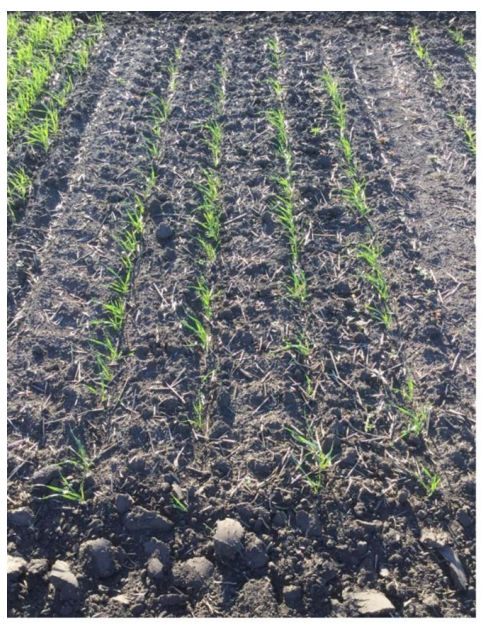

(a)

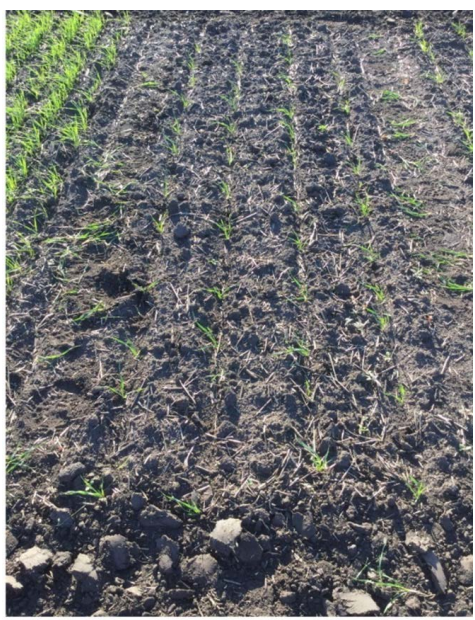

(b)

Figure 1. Experiment 2 plot of HRSW plants: (a) seeded at rate of 215,000 seeds $\mathrm{ha}^{-1}$; (b) same plot after thinning established plants to equidistant spacings of $30 \mathrm{~cm}$.

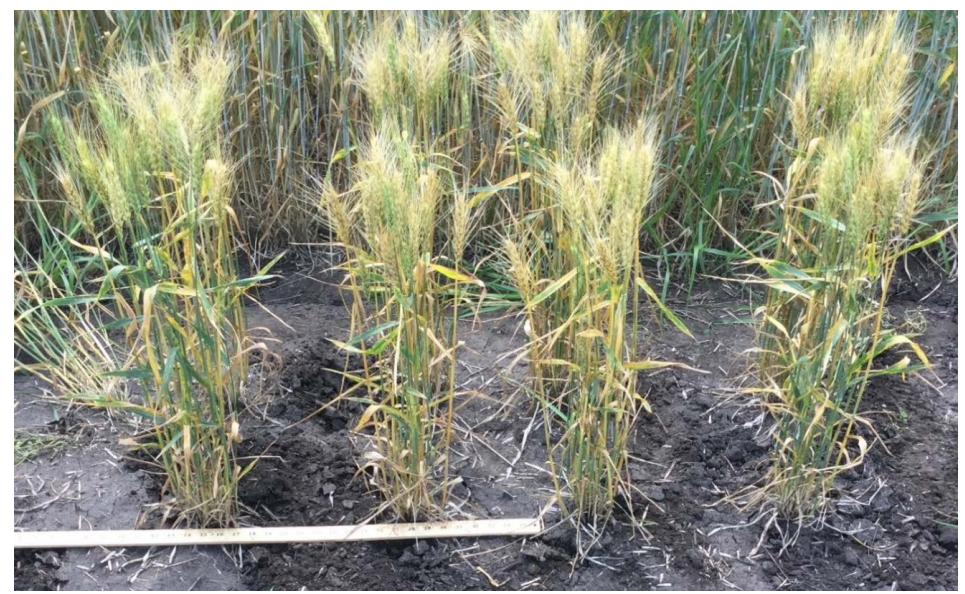

Figure 2. Intrarow spacing and spikes plant ${ }^{-1}$ were determined for eight plants selected from experimental plots at physiological maturity (Zadoks 89, [20]). 


\subsection{Statistical Analysis}

Analysis of variance of Experiment 1 data was performed for 2017 and 2018 environments using PROC MIXED in SAS 9.4 (SAS Institute Inc., Cary, NC). Variance of environments was considered homogenous and data were combined for ANOVA. Following the approach outlined by Carmer et al. [23], environment was assigned a random effect, and fixed effects were cultivar and seeding rate. A one-way ANOVA was completed for Experiment 2 in PROC MIXED and for Experiment 3 in PROC GLIMMIX evaluating spikes plant ${ }^{-1}$ of cultivar treatments. Mean separations were completed according to F-protected LSD values $(P \leq 0.05)$ determined in PROC MIXED for Experiment 1 and Experiment 2, and PROC GLIMMIX for Experiment 3 as an unequal number of cultivar replicates were present.

\subsection{Parameterization Methods}

Three methods were evaluated as potential approaches for determining parameters for classifications of the tillering capacity rating system. These methods included the "Means Comparisons approach", the "Z-score approach", and the "Standardized Distribution approach".

For the "Mean Comparisons approach", SAS output for LSD mean separations of spikes plant ${ }^{-1}$ were used to assign parameters as qualifiers associated with each classification of the tillering capacity rating system (low, moderate, high). As an objective was to develop a standardized system that could be applied in various environmental settings, this required a robust system with the capacity to assign tillering capacity ratings to cultivar from diverse genetic backgrounds that were assessed in differing growing conditions. To account for the effects of these experiment-specific variables in regards to cultivar tillering expression, it was determined that cultivar tillering capacity should be evaluated only after accounting for potential differences in spike densities across experiments. This was done by using Z-score transformations for spikes plant ${ }^{-1}$ obser- $^{-}$ vations in each experiment. This approach has been utilized by numerous agricultural and ecological studies to account for variability across environments [24] [25] [26]. The "Z-score approach" proposed that standardized z-scores calculated from spikes plant ${ }^{-1}$ observations could be used to determine cultivar tillering capacity based on relative tillering performance of the cultivar. The "Z-score approach" required a data transformation step in SAS (PROC STANDARD) to calculate standardized $\mathrm{z}$-scores from observations for spikes plant $^{-1}$ as:

$$
\text { z-score }=(x-\bar{x}) / s
$$

where $x$ is observed spikes plant ${ }^{-1}, \bar{x}$ is experimental mean, and $s$ is experimental standard deviation [27]. This adjusted the scale of plant response for spikes plant ${ }^{-1}$ to have a mean of 0 , and standard deviation of 1 .

The "Standardized Distribution approach" was somewhat of a continuation of the "Z-score approach", as standardized z-scores were used to calculate spikes plant $^{-1}$ estimates to represent data relative to the distribution of the population 
as:

$$
\hat{x}=(\mathrm{z} \text {-score } * \sigma)+\mu
$$

where, $\hat{x}$ is estimated spikes plant ${ }^{-1}, \mathrm{z}$-score is the $\mathrm{z}$-score of the spikes plant ${ }^{-1}$ observation, $\sigma$ is the population standard deviation, and $\mu$ is population mean.

\section{Results}

\subsection{Assessing Cultivar Tillering}

\subsubsection{Experiment 1}

Results from the ANOVA of Experiment 1 revealed spikes plant ${ }^{-1}$ of cultivars were consistent across environments. As cultivars were of diverse genetic backgrounds and phenotypes, it was not surprising that spikes plant ${ }^{-1}$ differed among cultivars (Table 3 ). Cultivars with higher tiller number $\left(\geq 2.54\right.$ spikes plant $\left.^{-1}\right)$ included SY Valda, Prevail, and ND VitPro. Cultivars producing a moderate number of spikes were Surpass, Linkert, and Shelly, at spikes plant ${ }^{-1}$ of 2.50, 2.33, and 2.21 spikes plant ${ }^{-1}$, respectively. TCG Wildfire, LCS Anchor, and Lang-MN were low tillering cultivars $\left(<2.18\right.$ spikes plant $\left.^{-1}\right)$ in Experiment 1.

In Experiment 1, incremental increases in seeding rate had an inverse effect on spikes plant ${ }^{-1}$ (Table 4). An increase in seeding rate from 1.85 to 3.09 million seeds $\mathrm{ha}^{-1}$, reduced the number of spikes plant ${ }^{-1}$ from 3.3 to 2.5 spikes plant $^{-1}$, respectively. At the highest seeding rates of 4.32 and 5.56 million seeds $\mathrm{ha}^{-1}$, spikes plant ${ }^{-1}$ was the lowest at 1.9 and 1.8 spikes plant $^{-1}$, respectively. As a consistent decrease in spikes plant ${ }^{-1}$ was observed across cultivars seeded at increasing rates, agronomic management appeared to be a factor limiting cultivar tillering potential.

Table 3. Spikes plant ${ }^{-1}$ of HRSW cultivars observed in 2017-2018 environments, Prosper, ND.

\begin{tabular}{cc}
\hline Cultivar & Spikes plant $^{-1}$ \\
SY Valda & $2.64 \mathrm{a}^{1}$ \\
Prevail & $2.60 \mathrm{a}$ \\
ND VitPro & $2.54 \mathrm{ab}$ \\
Surpass & $2.50 \mathrm{abc}$ \\
Linkert & $2.33 \mathrm{abcd}$ \\
Shelly & $2.21 \mathrm{bcd}$ \\
TCG Wildfire & $2.17 \mathrm{bcd}$ \\
LCS Anchor & $2.15 \mathrm{~cd}$ \\
Lang-MN & $2.06 \mathrm{~d}$ \\
mean & 2.36 \\
LSD $(\alpha=0.05)$ & 0.38 \\
\hline
\end{tabular}

${ }^{1}$ Values with the same letter in a column are not significantly different according to Fisher's LSD test $(P>$ 0.05). 
Table 4. Spikes plant ${ }^{-1}$ of HRSW at varying seeding rates, 2017-2018 Prosper environments.

\begin{tabular}{cc}
\hline Seeding rate $\left(\right.$ million seeds $\left.\mathrm{ha}^{-1}\right)$ & Spikes plant \\
\hline 1.85 & $3.3 \mathrm{a}^{1}$ \\
3.09 & $2.5 \mathrm{~b}$ \\
4.32 & $1.9 \mathrm{c}$ \\
5.56 & $1.8 \mathrm{c}$ \\
mean & 2.4 \\
LSD $(\alpha=0.05)$ & 0.3 \\
CV & 18.0 \\
\hline
\end{tabular}

${ }^{1}$ Values with the same letter in a column are not significantly different according to Fisher's LSD test $(P>$ $0.05)$.

Though spikes plant ${ }^{-1}$ were influenced by seeding rate, changes in seeding rate did not differentially affect cultivar spikes plant ${ }^{-1}$ (Table 5 ). This is likely because it is expected that plants established in densely-seeded conditions will have greater intraspecies competition compared to plants in space-planted conditions. To further evaluate cultivar spikes plant ${ }^{-1}$ relative to seeding rate, cultivar spike counts from the 2018 environment were used for one-way ANOVA for each seeding rate factor level. The purpose of this was to evaluate each seeding rate level (seeding density) as a potential approach for assessing cultivar tillering capacity. Results in Table 5 indicate assessments to determine cultivar tillering capacity should not be completed in HRSW production fields, as spikes plant ${ }^{-1}$ was similar among cultivar at seeding rates greater than 1.85 million seeds $\mathrm{ha}^{-1}$.

\subsubsection{Experiment 2}

Spaced-plantings using the SOFATT method in Experiment 2 promoted cultivar expression of tillering phenotype, as mean spikes plant ${ }^{-1}$ was 22.1 spikes plant $^{-1}$ (Table 6). Cultivar diversity was apparent as responses in spikes plant ${ }^{-1}$ were normally distributed, and spikes plant ${ }^{-1}$ differed among cultivars. Cultivars with the greatest tillering were ND VitPro and Shelly at 25.9 spikes plant $^{-1}$ each. Cultivars with moderate tillering were Lang-MN and Prevail (each with 23.4 spikes plant $^{-1}$ ), and Surpass and LCS Anchor producing 21.3 and 21.0 spikes plant ${ }^{-1}$, respectively. Linkert, SY Valda, and TCG Wildfire were the lowest tillering cultivars, as all averaged $<20$ spikes plant ${ }^{-1}$.

An unexpected result in Experiment 2 was that Shelly was among the highest tillering cultivars, as this cultivar was one of the lower tillering cultivars in Experiment 1 (Table 4). This may represent adaptive abilities of this cultivar, allowing for adjustments in growth habit relative to the amount of intraspecies competition. Increased tillering expression with greater intra-row spacing may be represented by other cultivars, as spikes plant ${ }^{-1}$ were not correlated $(r=-0.23 ; P$ $=0.547)$ when comparing cultivars at 1.85 million seeds ha $^{-1}$ in Experiment 1 and at spaced-plantings in Experiment 2. However, this may not be the case as 
Table 5. Spikes plant ${ }^{-1}$ of HRSW cultivars at various seeding densities in 2018 at Prosper, ND.

\begin{tabular}{|c|c|c|c|c|}
\hline \multirow{2}{*}{ Cultivar } & \multicolumn{4}{|c|}{ Seeding rate (million seeds $\mathrm{ha}^{-1}$ ) } \\
\hline & 1.85 & 3.09 & 4.32 & 5.56 \\
\hline & \multicolumn{4}{|c|}{ spikes plant $^{-1}$} \\
\hline SY Valda & $3.63 \mathrm{a}^{1}$ & 2.74 & 2.44 & 1.97 \\
\hline Linkert & $3.55 \mathrm{ab}$ & 2.11 & 2.15 & 1.57 \\
\hline ND VitPro & $3.23 \mathrm{abc}$ & 2.8 & 2.19 & 1.96 \\
\hline Surpass & $3.22 \mathrm{abc}$ & 2.49 & 1.98 & 1.89 \\
\hline Shelly & 3.09abcd & 2.13 & 1.58 & 1.35 \\
\hline Prevail & $3.02 \mathrm{abcd}$ & 2.63 & 1.87 & 1.66 \\
\hline TCG Wildfire & $2.99 \mathrm{bcd}$ & 1.95 & 2.05 & 1.58 \\
\hline Lang-MN & $2.67 \mathrm{~cd}$ & 2.13 & 1.54 & 1.50 \\
\hline LCS Anchor & $2.50 \mathrm{~d}$ & 2.23 & 1.61 & 1.59 \\
\hline Mean & 3.10 & 2.36 & 1.93 & 1.68 \\
\hline $\operatorname{LSD}(\alpha=0.05)$ & 0.64 & NS & NS & NS \\
\hline Seeding rate & \multicolumn{4}{|c|}{ Pearson's correlation coefficient $(r)$} \\
\hline 1.85 vs 3.09 & \multicolumn{2}{|c|}{$0.40^{\mathrm{NS}}$} & & \\
\hline 3.09 vs 4.32 & \multicolumn{4}{|c|}{$0.52^{\mathrm{NS}}$} \\
\hline 4.32 vs 5.56 & & & \multicolumn{2}{|c|}{$0.76^{*}$} \\
\hline
\end{tabular}

${ }^{1}$ Values with the same letter in a column are not significantly different $(P>0.05) .{ }^{*}$ Significant at $P \leq 0.05$; NS, not significant.

Table 6. Spikes plant ${ }^{-1}$ of HRSW cultivars in space-planted experiments, Prosper 2018.

\begin{tabular}{ccc}
\hline & Experiment 2 & Experiment 3 \\
\cline { 2 - 3 } Cultivar & \multicolumn{2}{c}{${\text { spikes plant }{ }^{-1}}^{2}$} \\
\hline Shelly & $25.9 \mathrm{a}^{1}$ & $23.1 \mathrm{bc}$ \\
ND VitPro & $25.9 \mathrm{a}$ & $26.6 \mathrm{a}$ \\
Lang-MN & $23.4 \mathrm{ab}$ & $23.5 \mathrm{bc}$ \\
Prevail & $23.4 \mathrm{ab}$ & $26.4 \mathrm{ab}$ \\
Surpass & $21.3 \mathrm{bc}$ & $22.0 \mathrm{~cd}$ \\
LCS Anchor & $21.0 \mathrm{bc}$ & $21.8 \mathrm{~cd}$ \\
Linkert & $19.5 \mathrm{c}$ & $22.2 \mathrm{~cd}$ \\
SY Valda & $19.5 \mathrm{c}$ & $20.5 \mathrm{~cd}$ \\
TCG Wildfire & $18.9 \mathrm{c}$ & $19.7 \mathrm{~d}$ \\
Mean & 22.1 & 22.9 \\
CV & 11.4 & 21.5
\end{tabular}

${ }^{1}$ Values with the same letter in a column are not different based on Fisher's LSD $(P>0.05)$. 
there was no interaction for cultivar by seeding rate in Experiment 1, and Shelly did not have an apparent advantage over other cultivars when different seeding density methods were used to assess tillering capacity of cultivars.

\subsubsection{Experiment 3}

Experiment 3 had poor emergence and uneven establishment across replicates, which was attributed to dry soil conditions at planting. Spikes plant ${ }^{-1}$ differed among cultivar at spaced-plantings used in Experiment 3, and the mean spikes plant $^{-1}$ was 22.9 spikes plant $^{-1}$ (Table 6). The highest tillering cultivar was ND VitPro (26.6 spikes plant ${ }^{-1}$ ). The cultivar with the lowest number of tillers was TCG Wildfire with 19.7 spikes plant $^{-1}$. The six other cultivars had tillering that ranged from 20.5 to 26.4 spikes plant ${ }^{-1}$. The lack of differences among cultivars was a result of high standard error values due to the broad range of spikes plant $^{-1}$ observed for each cultivar (Figure 3 ). Due to the poor establishment of Experiment 3 and high variability in results, no comparisons were made between Experiment 3 and the other experiments evaluated in this study.

\subsection{Determining Cultivar Tillering Capacity}

\subsubsection{Parameterization Methods}

Three parameterization methods were identified as potential approaches for differentiating the classes selected for the tillering capacity rating system (low, moderate, and high). Parameters determined by the "Mean Comparisons approach" (using letters from mean separations based on LSD values) were selected based on SAS output for mean separations $(P \leq 0.05)$ for cultivar spikes plant $^{-1}$ in Experiment 2 (Table 6). As four groupings of cultivars were indicated by mean comparisons based on Fisher's LSD, parameters for each rating class were relatively easy to distinguish (Table 7).

Parameterization by the "Z-score approach" (data transformation to standardized z-score values) provided a quantitative method for determining cultivar

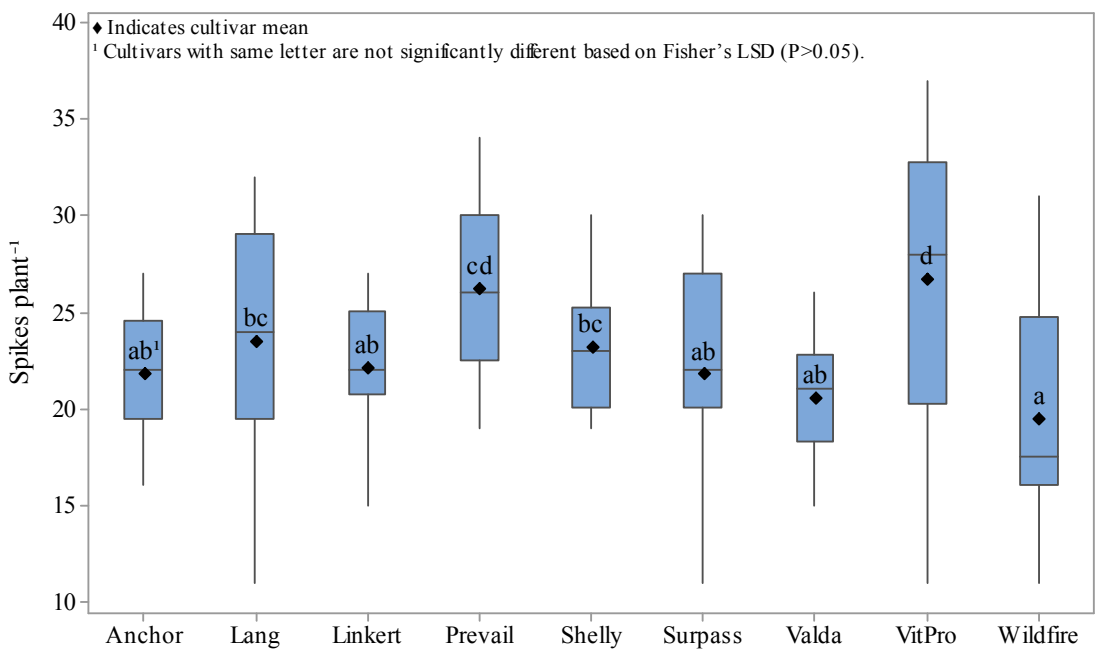

Figure 3. Spikes plant ${ }^{-1}$ of HRSW cultivars evaluated at spaced-plantings in Experiment 3. 
Table 7. Parameterization used for grouping HRSW cultivars based on tillering capacity in Experiment 2.

\begin{tabular}{cccc}
\hline & \multicolumn{3}{c}{ Tillering capacity } \\
\hline Parameterization method & Low & Moderate & High \\
\hline Mean separations ${ }^{1}$ & $\mathrm{a}$ & $\mathrm{ab} / \mathrm{bc}$ & $\mathrm{c}$ \\
Z-score & $<-0.6745$ & -0.6745 to 0.6745 & $>0.6745$ \\
Spikes plant $^{-1}(\text { est. })^{2}$ & $<19.7$ & 19.7 to 24.4 & $>24.4$ \\
\hline
\end{tabular}

${ }^{1}$ Based on F-protected LSD values $(\alpha=0.05) .{ }^{2}$ Estimated spikes plant ${ }^{-1}$ based on standardized distribution; calculated as: population mean $\pm 0.6745^{*}$ standard deviation of population.

tillering capacity ratings. As spikes plant ${ }^{-1}$ responses in Experiment 2 followed a normal distribution, $\mathrm{z}$-score values at the first quartile (Q1) and third quartile (Q3) were used as parameters for assigning tillering capacity ratings (Table 7). Cultivar with an average $z$-score of $<-0.6745$ were considered to have a low tillering capacity. Cultivar with a $\mathrm{z}$-score $\geq-0.6745$ and $\leq 0.6745$ were considered to have a moderate tillering capacity. Cultivar with a high tillering capacity had a $z$-score $>0.6745$. This parameterization method was very easy to complete, and interpretation of results is not limited to the dataset evaluated, as data were adjusted to a standardized scale, with a mean of zero and standard deviation of one.

Z-scores for cultivar spikes plant ${ }^{-1}$ can be readily compared across experiments to determine relative tillering of cultivars in differing environments. This was best demonstrated by comparing results from Experiment 1 and Experiment 2. Though expression of tillering phenotypes was limited in Experiment 1, differences in spikes plant ${ }^{-1}$ were observed among cultivar. These results were used to demonstrate cultivar tillering response at densities present in grower production fields (Experiment 1) compared to growth in spaced-plantings (Experiment 2). To account for the large difference in mean spikes plant ${ }^{-1}$ between Experiment 1 and Experiment 2, standardized z-score values were calculated for spikes plant $^{-1}$ observations in each experiment. This adjusted the response scale of each experiment to be on the same relative scale (Figure 4).

The "Standardized Distribution approach" (standardized z-scores transformed to spikes plant ${ }^{-1}$ estimates based on population distribution) was the third parameterization method used. For this method, parameters for tillering capacity ratings were set at Q1 and Q3, and represented as estimated values for spikes plant $^{-1}$, where $\mu=22.1$ and $\sigma=3.5$. Spikes plant ${ }^{-1}$ was estimated at 19.7 and 24.4 spikes plant ${ }^{-1}$ at Q1 and Q3, respectively (Table 7). This method is most relevant for application in future tillering studies.

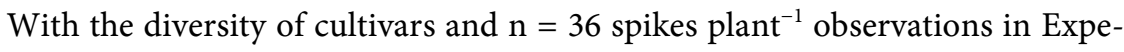
riment 2, it was surmised that results from Experiment 2 were representative of most HRSW cultivars currently available to growers for production. Therefore, the spikes plant ${ }^{-1}$ parameters outlined in Table 7 can be readily used by researchers to determine tillering capacity of cultivar when using the tillering 


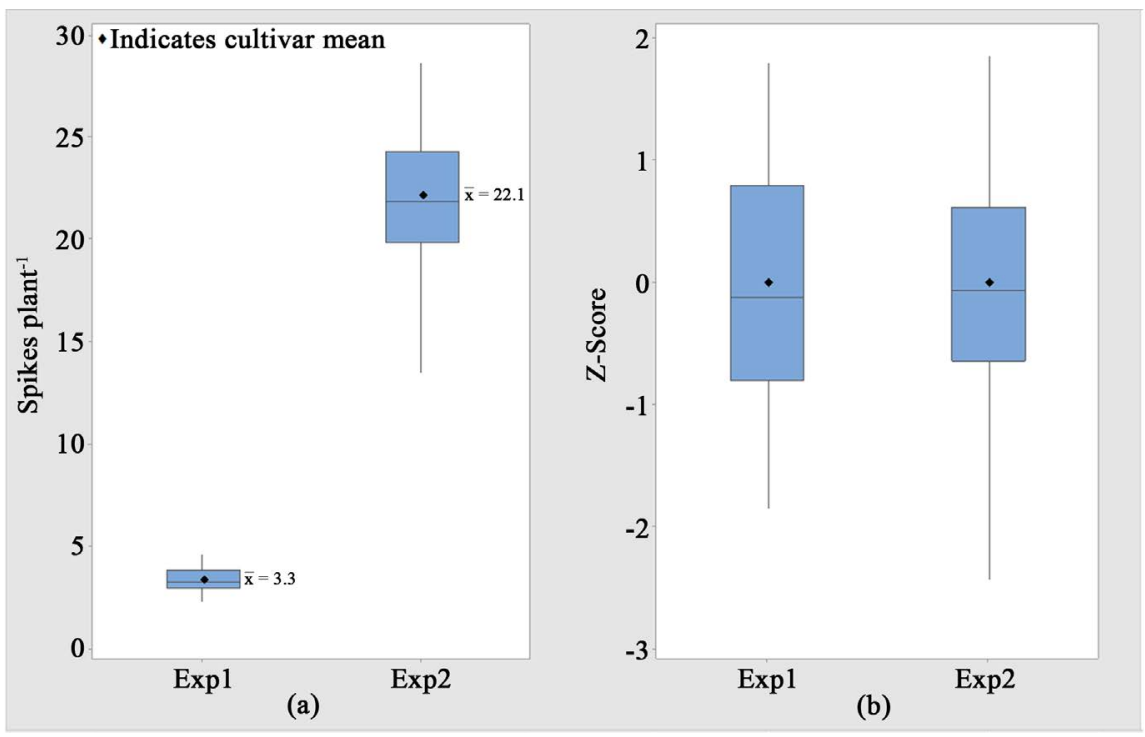

Figure 4. Observations for spikes plant ${ }^{-1}$ as: (a) Standardized Z-scores based on transformed values for spikes plant ${ }^{-1}$; (b) Observed in Experiment 1 and Experiment 2 at Prosper, North Dakota in 2018.

assessment method from Experiment 2. If the mean and standard deviation of any subsequent experiments were to differ from the population $(\mu=22.1 ; \sigma=$ 3.5), values from the subsequent experiment could be considered samples of the population, and thereby readily adjusted by solving for $\mathrm{x}$ (estimated spikes plant $^{-1}$ ) in the $z$-score equation, using the $z$-score for the sampled value, and the standardized distribution for the population $(\mu, \sigma)$.

\subsubsection{Cultivar Tillering Profiles}

The ranking for tillering capacity was similar across parameterization methods for each cultivar (Table 8). Shelly and ND VitPro have a relatively high tillering capacity, whereas Linkert, SY Valda, and TCG Wildfire have relatively low tillering capacity. Cultivars with moderate capacity for tillering include LCS Anchor, Surpass, Prevail, and Lang-MN. Genetic associations with plant tillering may be represented in Experiment 2 results, as cultivars with similar expression for a particular trait have the same tillering capacity rating. This was demonstrated by the high tillering capacity cultivars (Shelly and ND VitPro), which are both photoperiod insensitive $(P p d-D 1 b)$ and express the Rht-B1 gene for semidwarf phenotype. Conversely, as other photoperiod insensitive cultivars (Linkert and SY Valda) have a low tillering capacity, this may indicate influences from other genes potentially associated with plant tillering response. These low tillering cultivars also have a semi-dwarf phenotype; however, this phenotype is imparted by $R h t-D 1$ semi-dwarf gene expression.

Tiller density, spikes plant ${ }^{-1}$, and tillering capacity did not have an apparent influence on tiller mortality of cultivars. As tiller mortality differed among cultivars in Experiment 2, these results indicate tiller production and survival is likely influenced primarily by wheat genotype (Figure 5). 


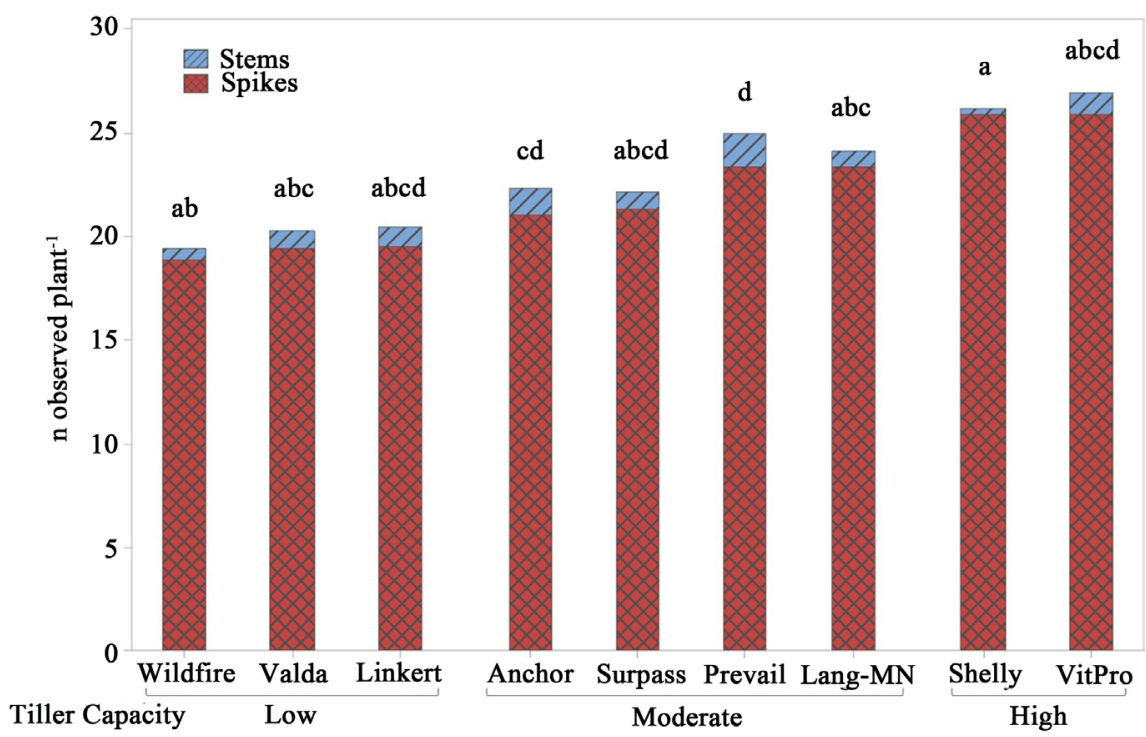

Figure 5. Stem and spikes plant ${ }^{-1}$ (difference represents tiller mortality) of HRSW cultivars in spaced-plantings in Experiment 2 at Prosper, ND in 2018. Mean separations for tiller mortality were determined by Fisher's LSD test, where cultivar with same letter are not significantly different $(P>0.05)$.

Table 8. Tillering capacity of HRSW cultivars as determined by three parameterization methods.

\begin{tabular}{|c|c|c|c|c|c|c|c|c|}
\hline \multirow{3}{*}{$\begin{array}{l}\text { Cultivar } \\
\text { Shelly }\end{array}$} & \multirow{3}{*}{$\begin{array}{l}\text { Photoperiod } \\
\text { response }\end{array}$} & \multirow{3}{*}{$\begin{array}{c}\begin{array}{c}\text { Dwarfing } \\
\text { gene }\end{array} \\
\text { Rht-B1 }\end{array}$} & \multicolumn{6}{|c|}{ Method } \\
\hline & & & \multicolumn{2}{|c|}{$\begin{array}{c}\text { Mean } \\
\text { comparisons }\end{array}$} & \multicolumn{2}{|c|}{ Z-score } & \multicolumn{2}{|c|}{$\begin{array}{c}\text { Spikes plant }{ }^{-1} \\
\text { (est.) }\end{array}$} \\
\hline & & & $a^{2}$ & $\mathrm{H}^{3}$ & 1.10 & $\mathrm{H}$ & 25.9 & $\mathrm{H}$ \\
\hline ND VitPro & Insensitive & $R h t-B 1$ & a & $\mathrm{H}$ & 1.10 & $\mathrm{H}$ & 25.9 & $\mathrm{H}$ \\
\hline Prevail & Sensitive & Wild-type & $\mathrm{ab}$ & M & 0.37 & M & 23.4 & M \\
\hline Lang-MN & Sensitive & Wild-type & $\mathrm{ab}$ & M & 0.38 & M & 23.4 & M \\
\hline Surpass & Insensitive & Wild-type & $\mathrm{bc}$ & M & -0.23 & M & 21.3 & M \\
\hline LCS Anchor & Sensitive & $R h t-D 1$ & $\mathrm{bc}$ & M & -0.31 & M & 21.0 & M \\
\hline SY Valda & Insensitive & $R h t-D 1$ & c & $\mathrm{L}$ & -0.75 & $\mathrm{~L}$ & 19.5 & $\mathrm{~L}$ \\
\hline Linkert & Insensitive & $R h t-D 1$ & c & $\mathrm{L}$ & -0.73 & $\mathrm{~L}$ & 19.5 & $\mathrm{~L}$ \\
\hline TCG Wildfire $^{1}$ & Sensitive & $R h t-B 1$ & c & $\mathrm{L}$ & -0.92 & $\mathrm{~L}$ & 18.9 & $\mathrm{~L}$ \\
\hline
\end{tabular}

${ }^{1}$ Cultivar ranked by tillering capacity; low to high. ${ }^{2}$ Mean comparisons based on Fisher's LSD test $(P \leq 0.05)$. ${ }^{3}$ Tillering capacity; where $\mathrm{L}$ is low, $\mathrm{M}$ is moderate, and $\mathrm{H}$ is high tillering cultivar.

Though tiller mortality differed among cultivars, tiller production and survival were consistent for all cultivars as indicated by high correlation coefficients ( $r$ $\geq 0.93$ ) between stem density and spikes plant ${ }^{-1}$ (Table 9 ). Lang-MN and Surpass appear to have produced a more variable number of yield-contributing spikes relative to the number of tillers formed. Overall, this reveals that wheat plants may self-regulate tiller formation to consistently produce a certain number of viable spikes relative to the number of tillers formed. 
Table 9. Spikes plant ${ }^{-1}$ of HRSW cultivars in spaced-plantings in Experiment 2, Prosper 2018.

\begin{tabular}{|c|c|c|c|c|c|}
\hline \multirow{2}{*}{ Cultivar } & Tillers plant $^{-1}$ & Spikes plant ${ }^{-1}$ & Tiller mortality ${ }^{1}$ & \multirow{2}{*}{$r$} & \multirow{2}{*}{$\operatorname{Pr}>|r|$} \\
\hline & stems plant ${ }^{-1}$ & spikes plant ${ }^{-1}$ & $\mathrm{n}$ plant ${ }^{-1}$ & & \\
\hline TCG Wildfire ${ }^{2}$ & 19.4 & 18.9 & 0.5 & 0.99 & 0.006 \\
\hline SY Valda & 20.3 & 19.5 & 0.8 & 0.98 & 0.021 \\
\hline Linkert & 20.5 & 19.5 & 1.0 & 0.99 & 0.003 \\
\hline LCS Anchor & 22.3 & 21.0 & 1.3 & 0.97 & 0.026 \\
\hline Surpass & 22.2 & 21.3 & 0.9 & 0.93 & 0.066 \\
\hline Prevail & 25.0 & 23.4 & 1.6 & 0.98 & 0.020 \\
\hline Lang-MN & 24.1 & 23.4 & 0.7 & 0.94 & 0.057 \\
\hline Shelly & 26.2 & 25.9 & 0.3 & 0.99 & 0.001 \\
\hline ND VitPro & 27.0 & 25.9 & 1.1 & 0.99 & 0.003 \\
\hline Experimentwise & 23.0 & 22.1 & 0.9 & 0.99 & $<0.0001$ \\
\hline $\operatorname{LSD}(\alpha=0.05)$ & 3.7 & 3.0 & 0.7 & & \\
\hline
\end{tabular}

${ }^{1}$ Tiller mortality $=\left(\right.$ stems plant ${ }^{-1}-$ spikes plant $\left.{ }^{-1}\right) .{ }^{2}$ Ranked by tillering capacity; low to high. ${ }^{3} \mathrm{LSD}$ value based on Fisher's F-protected test $(P \leq 0.05)$.

\subsubsection{Method Validation}

To validate the application of these approaches for determining cultivar tillering capacity, experimental means from eight similar space-planted tillering studies conducted at Prosper, ND and Crookston, MN in 2014 and 2015 were used to determine tillering capacity of $12 \mathrm{HRSW}$ cultivars (Table 10). Observations for tiller density (stems plant ${ }^{-1}$ ) were used for this validation, as spikes plant ${ }^{-1}$ was not reported. Z-scores and standardized values for cultivar tiller density guided the selection of tillering capacity rating for each cultivar (Table 10).

Results for the validation set were similar to Experiment 2 results as interactions between photoperiod gene $P p d-D 1$ and semi-dwarfing genes (Rht-B1 and $R h t-D 1)$ appear to be associated with plant tillering response. The most revealing finding is that the two cultivars that are photoperiod insensitive ( $P p d-D 1 a)$ and express the Rht-B1b allele, have a high tillering capacity. This response is similar to what was revealed in Experiment 2, as Shelly and ND VitPro are both cultivars with high tillering capacity and share similar genetic traits (Table 8).

Cultivars with photoperiod sensitivity appeared to have variable tillering capacity profiles, as no apparent groupings were observed for sensitive cultivars with similar genetic background for traits affecting plant stature. As data were compiled over multiple environments, it is likely that these results represent a robust assessment of tillering habit of these cultivars, sufficient to determine the tillering capacity that accurately characterizes each cultivar.

\section{Discussion}

The observations that spikes plant ${ }^{-1}$ of cultivars were consistent across environments are in line with findings of Klepper et al. [16]. This offers support that 
Table 10. Tillering of HRSW cultivars in space-planted experiments in North Dakota and Minnesota, 2014-2015.

\begin{tabular}{ccccccc}
\hline Cultivar & $\begin{array}{c}\text { Photoperiod } \\
\text { response }\end{array}$ & $\begin{array}{c}\text { Dwarfing } \\
\text { gene }\end{array}$ & $\begin{array}{c}\text { Observed } \\
\text { stems plant }\end{array}$ & $\begin{array}{c}\text { Standardized } \\
\text { stems plant }{ }^{-1}\end{array}$ & Z-score & $\begin{array}{c}\text { Tillering } \\
\text { capacity }\end{array}$ \\
\hline Faller ${ }^{1}$ & Insensitive & Rht- $B 1$ & 29.7 & $28.1^{2}$ & 1.48 & $\mathrm{H}^{3}$ \\
Sabin & Sensitive & Wild-type & 28.9 & 27.4 & 1.29 & $\mathrm{H}$ \\
Albany & Insensitive & Rht-B1 & 28.3 & 27.0 & 1.15 & $\mathrm{H}$ \\
Marshall & Insensitive & Rht-D1 & 26.1 & 25.2 & 0.63 & $\mathrm{M}$ \\
Knudson & Sensitive & Rht- $B 1$ & 25.8 & 24.9 & 0.56 & $\mathrm{M}$ \\
Vantage & Insensitive & Wild-type & 23.2 & 22.8 & -0.04 & $\mathrm{M}$ \\
Kuntz & Sensitive & Rht-D1 & 22 & 21.9 & -0.33 & $\mathrm{M}$ \\
Rollag & Insensitive & Rht-D1 & 20.6 & 20.8 & -0.65 & $\mathrm{M}$ \\
Oklee & Sensitive & Wild-type & 20.4 & 20.6 & -0.7 & $\mathrm{~L}$ \\
Briggs & Insensitive & Wild-type & 19.6 & 19.9 & -0.89 & $\mathrm{~L}$ \\
Kelby & Sensitive & Rht- $D 1$ & 19.3 & 19.7 & -0.96 & $\mathrm{~L}$ \\
Samson & Sensitive & Rht- $B 1$ & 16.8 & 17.7 & -1.54 & $\mathrm{~L}$ \\
Mean & & & 23.4 & 23.0 & 0.00 & \\
Std. Dev. & & & 4.3 & 3.4 & 1.00 & \\
\hline
\end{tabular}

${ }^{1}$ Cultivar ranked by tillering capacity; low to high. ${ }^{2}$ Based on standardized distribution of $z$-scores with $\mu=$ 23.0 and $\sigma=3.4$ stems plant ${ }^{-1} .{ }^{3}$ Tillering capacity rating based on $\mathrm{z}$-score parameterization; L, low; M, moderate; $\mathrm{H}$, high.

seasonal differences in environmental conditions are not likely to influence results when assessing tillering of wheat cultivars to determine tillering capacity. It was apparent that plant spacing affected spike production, as incremental increases in seeding rate had an inverse effect on spikes plant ${ }^{-1}$ (Table 4). Similar responses to seeding rate were reported by Joseph et al. [28], where 3.7, 2.3, and 1.8 spikes plant ${ }^{-1}$ were observed at a seeding rate of $1.86,3.72$, and 5.58 million seeds $\mathrm{ha}^{-1}$, respectively. Other studies have indicated similar negative trends in number of spikes plant ${ }^{-1}$ as plant density increased, including observations of $29.4,18.6,7.2,2.1$, and 0.7 spikes plant $^{-1}$ at 1.4, 7, 35, 184, and 1078 plants $\mathrm{m}^{-2}$, respectively, and reduction in spikes from 5.6 to 3.1 spikes plant ${ }^{-1}$, as plant density was increased from 75 to 200 plants $\mathrm{m}^{-2}$ [29] [30]. As a consistent decrease in spikes plant ${ }^{-1}$ was observed across cultivars seeded at increasing rates, it is apparent that seeding density can limit cultivar tillering potential.

Though spikes plant ${ }^{-1}$ was influenced by seeding rate, changes in seeding rate did not differentially affect cultivar spikes plant ${ }^{-1}$ (Table 5). Simmons et al. [31] reported similar findings for barley genotypes that varied in tillering capacity. Cultivar differences in tillering capacity and growth habit may explain why greater differences were not seen among cultivars seeded at different rates in Experiment 1. Plants established in densely-seeded conditions are expected to have greater intraspecies competition compared to plants in space-planted con- 
ditions. As neighboring plants compete for available resources, growth habit can vary depending on the intensity of competition among rivaling intraspecies and interspecies plants [32] [33]. Though differences in spikes plant ${ }^{-1}$ were observed among cultivar seeded at 1.85 million seeds $\mathrm{ha}^{-1}$, the differences were minimal and not likely to be readily detected in field evaluations. However, it is still important to note that spikes plant ${ }^{-1}$ of cultivars became more dissimilar as seeding rate decreased. This is supported by the increased cultivar expression of tillering habit with incremental decreases in seeding rate that was represented by a continual decrease in correlation coefficient $(r)$ values when comparing treatments (Table 5). Experiment 1 confirmed the effects of plant density on HRSW tillering, primarily in relation to the level of competition among neighboring plants. As a consistent decrease in spikes plant ${ }^{-1}$ was observed across cultivars as seeding rate increased, tillering assessments based on plants seeded at production-level densities ( 1.85 to 5.56 million seeds $\mathrm{ha}^{-1}$ ) will not represent the full tillering capacity of a cultivar.

The high standard error observed in Experiment 3 could be attributed to the unfavorable environmental conditions at varying intensity throughout the site, and additional error within the experiment $(\mathrm{CV}=21.5)$ that was unaccounted for (Table 6). Based on these results, the space-planted method used in Experiment 3 is not likely to provide an accurate assessment of tillering of wheat cultivars.

Results for the three experiments assessing cultivar tillering indicate spacedplantings provided for the most accurate assessment of cultivar tillering. As results for cultivar spikes plant ${ }^{-1}$ in Experiment 3 were correlated with Experiment 2 results $(r=0.79 ; P=0.011)$, this indicates that both space-planted methods provided for similar tillering expression of cultivars. However, cultivar tillering habit was best represented by average spikes plant ${ }^{-1}$ of multiple plants sampled from a cultivar grown at spaced-plantings (inter-row and intra-row spacing at 30 $\pm 12 \mathrm{~cm}$ ). In general, assessing cultivar tillering to determine tillering capacity was best represented by the SOFATT method used in Experiment 2. This is likely because the greater growing area of the experimental units helped minimize experimental error and maximize tillering potential of cultivars. Limited competition from neighboring plants promoted phenotypic expression of tillering, providing for an accurate assessment of cultivar tillering abilities. Based on these findings, spaced-plantings are needed to properly assess tillering of wheat cultivars.

Considering the three parameterization methods proposed in this study, the "Mean Comparisons approach" was the easiest as it readily provided four groupings of cultivars to be used as parameters for each rating class (Table 7). However, in experiments where the number of treatments or level of precision results in greater than four groupings of letters, defining parameters for each tillering capacity rating class would be a highly subjective process. Also, in experiments with unequal replication where alternative mean separations tests (such as Tukey procedure, or Tukey-Kramer test [34]) are most appropriate, results 
would not be readily comparable across experiments. As these factors are additional sources of error and uncertainty that are not easy to account for, this is likely the reasoning why there is currently no standardized method that is widely used to assign tillering capacity ratings to wheat cultivars.

Parameterization by the "Z-score approach" provided a quantitative method for readily determining cultivar tillering capacity ratings. This method is favorable for researchers and breeders as the parameterization was very easy to complete, and interpretation of results is not limited to the dataset evaluated. Researchers in other wheat production regions could utilize this approach to determine tillering capacity of cultivars that are adapted for their region. Assuming a sufficient number of diverse cultivars are included in initial tillering evaluation trials to ensure a dataset with a normal distribution, $\mathrm{z}$-score values at the first quartile (Q1) and third quartile (Q3) could be used as parameters for assigning tillering capacity ratings (similar to Table 7). As region-specific data would be adjusted to a standardized scale (with a mean of zero and standard deviation of one), z-scores for cultivar spikes plant ${ }^{-1}$ could be readily compared across experiments to determine relative tillering of cultivars in differing environments (similar to the example in Figure 4). Though data from Experiment 1 data were not used to determine cultivar tillering capacity, Figure 4 demonstrates how $\mathrm{z}$-scores can be used to standardize observations to a scale that is relative to the experimental mean. Therefore, relative response of a cultivar can be compared when more than one experimental dataset is used to determine cultivar tillering capacity.

The "Standardized Distribution approach" could be used by researchers and breeders to assign cultivar tillering capacity ratings once initial parameters are established using the "Z-score approach". This would eliminate the need for excessive evaluation trials that continuously include a sufficient diversity in cultivars to ensure a normal distribution required for establishing parameters if the "Z-score approach" was used alone. Once the population mean and standard deviation are determined from initial tillering studies, these values can be used with the "Standardized Distribution approach" to readily assign tillering capacity ratings based on observations for spikes plant ${ }^{-1}$. As breeding programs are likely already documenting this information in spaced-plantings of their advanced wheat lines, this data could be readily utilized to assign a tillering capacity rating to further characterize cultivars when released.

Prior studies in barley indicated the importance of evaluating phenotypic characteristics such as tiller density (stems plant ${ }^{-1}$ ) relative to the number of spikes plant ${ }^{-1}$, as tiller mortality differs with genotype and can negatively impact grain yield [35] [36]. As tiller mortality differed among cultivars in Experiment 2 , these results offer additional support to the understanding that genotype greatly influences tiller mortality. These observations also revealed the importance of considering the plant structure used to assess and determine tillering capacity of wheat cultivars, as determining tillering capacity based on stems plant $^{-1}$ could potentially lead to a different tillering capacity than when based on 
spikes plant ${ }^{-1}$. Though this is an important consideration, this was not the case in Experiment 2 as cultivar tillering capacity based on stems plant ${ }^{-1}$ or spikes plant $^{-1}$ arrived at the same tillering capacity rating (results not included). As spikes plant ${ }^{-1}$ is a primary component of wheat yield, cultivar tillering capacity based on spikes plant ${ }^{-1}$ is more relevant to growers making seeding and crop management decisions; especially as not all tillers formed will produce spikes that contribute to the final yield.

As there was inconsistency in tillering expression among cultivars relative to specific genetic traits, tillering habit was not attributable to a single genetic trait of the three evaluated. Contrasting responses among cultivar sharing similar genetic traits may represent the effects of $P p d-D 1$ interactions with other genes as discussed by Gonzalez et al. [37]. However, trends in tillering habit were apparent among cultivars sharing similar backgrounds for multiple genetic traits (Table 8). Interactions between photoperiod gene $P p d-D 1$ and semi-dwarfing genes (Rht-B1 and Rht-D1) appeared to influence plant tillering response. The most revealing finding was that the cultivars that are both photoperiod insensitive $(P p d-D 1 a)$ and express the Rht-B1b allele for semi-dwarf phenotype, all have a high tillering capacity rating (Table 8 and Table 10). This response could be influenced by QTL reported by Borras-Gelonch [38], who indicated QTLs at a similar locus were associated with tillering and phenology characteristics. Eagles et al. [39] suggested $P p d-D 1$ interactions with alternate gene(s) (that also have effect on tillering) as a possible explanation for contrasting yield responses observed in genotypes with similar genetic background for $P p d-D 1$. In comparison to these high tillering cultivars, the photoperiod insensitive cultivars with Rht-D1 gene have a moderate tillering capacity. As it has been noted by Addisu et al. [40] that $R h t-D 1$ plants can have reduced biomass and greater harvest index in comparison to $R h t-B 1$ plants, these differences in tillering capacity observed in photoperiod insensitive cultivars are understandable. Overall, as a potential interactive effect of $P p d-D 1 a \times R h t-B 1 b$ on tillering habit has not been previously reported, this association would be important to consider exploring in future studies.

\section{Conclusion}

Plants grown at high population densities in grower production fields are not likely to represent full tillering potential of a cultivar, therefore it is necessary to utilize spaced-plantings to properly assess tillering habits of wheat cultivars. Assessing cultivar tillering to determine tillering capacity was best represented by the SOFATT method, where average spikes plant $^{-1}$ was determined from multiple plants sampled from a cultivar grown at spaced-plantings (inter-row and intra-row spacing at $30 \pm 12 \mathrm{~cm}$ ). Researchers can use results for average spikes plant $^{-1}$ to determine tillering capacity rating for each cultivar, based on raw or transformed $z$-score values for spikes plant ${ }^{-1}$. The Z-score approach is most relevant for researchers evaluating a diverse selection of wheat genotypes (e.g. advanced breeding lines, variety trials). The Standardized Distribution approach is 
also useful, as researchers can establish values for spikes plant ${ }^{-1}$ that can be used as parameters in future studies to readily determine cultivar tillering capacity rating.

\section{Conflicts of Interest}

The authors declare no conflict of interest. Author J.D.S. was employed by Syngenta Crop Protection, LLC after completion of the experiments. G.H.M. was employed by Bayer CropScience after completion of the 2014-2015 experiments. The funders had no role in the design of the study; in the collection, analyses, or interpretation of data; in the writing of the manuscript, or in the decision to publish the results.

\section{References}

[1] Fischer, R.A. (2001) Selection Traits for Improving Yield Potential. In: Reynolds, A.P., Ortiz-Monasterio, J.I. and McNab, A., Eds., Application of Physiology in Wheat Breeding, CIMMYT, Mexico, 148-159.

[2] Woodruff, D.R. and Tonks, J. (1983) Relationship between Time of Anthesis and Grain Yield of Wheat Genotypes with Differing Developmental Pattern. Australian Journal of Agricultural Research, 34, 1-11. https://doi.org/10.1071/AR9830001

[3] Donald, C.M. (1968) The Breeding of Crop Ideotypes. Euphytica, 17, 385-403. https://doi.org/10.1007/BF00056241

[4] Kirby, E.J.M. and Faris, D.G. (1972) The Effect of Plant Density on Tiller Growth and Morphology in Barley. Journal of Agricultural Science, Cambridge, 78, 281-288. https://doi.org/10.1017/S0021859600069124

[5] Richards, R.A. (1988) A Tiller Inhibitor Gene in Wheat and Its Effect on Plant Growth. Australian Journal of Agricultural Research, 39, 749-757.

https://doi.org/10.1071/AR9880749

[6] Li, W.I., Nelson, J.C., Chu, C.Y., Shi, L.H., Huang, S.H. and Liu, D.J. (2002) Chromosomal Locations and Genetic Relationships of Tiller and Spike Characters in Wheat. Euphytica, 125, 357-366. https://doi.org/10.1023/A:1016069809977

[7] Destro, D., Miglioranza, E., Arrabal Arias, C.A., Vendrame, J.M. and Vieira de Almeida, J.C. (2001) Main Stem and Tiller Contribution to Wheat Cultivars Yield under Different Irrigation Regimes. Brazilian Archives of Biology and Technology, 44, 325-330. https://doi.org/10.1590/S1516-89132001000400001

[8] Otteson, B.N., Mergourm, M. and Ransom, J.K. (2007) Seeding Rate and Nitrogen Management Effects on Spring Wheat Yield and Yield Components. Agronomy Journal, 99, 1615-1621. https://doi.org/10.2134/agronj2007.0002

[9] Fisher, R.A. and Kohn, G.D. (1966) The Relationship of Grain Yield to Vegetative Growth and Post-Flowering Leaf Area in the Wheat Crop under Conditions of Limited Soil Moisture. Australian Journal of Agricultural Research, 17, 281-295. https://doi.org/10.1071/AR9660281

[10] Richards, R.A. and Townley-Smith, T.F. (1987) Variation in Leaf Area Development and Its Effect on Water Use, Yield and Harvest Index of Droughted Wheat. Australian Journal of Agricultural Research, 38, 983-992. https://doi.org/10.1071/AR9870983

[11] Hsu, P. and Walton, P.D. (1971) Relationships between Yield and Its Components and Structures above the Flag Leaf Node in Spring Wheat. Crop Science, 2, 190-193. 
https://doi.org/10.2135/cropsci1971.0011183X001100020007x

[12] Holliday, R. (1960) Plant Population and Crop Yield: Part I. Field Crop Abstracts, 13, 159-167.

[13] Archbold, H.K. and Mukerjee, B.N. (1942) Physiological Studies in Plant Nutrition: XII. Carbohydrate Changes in the Several Organs of the Barley Plant during Growth, with Especial Reference to the Development and Ripening of the Ear. Annals of Botany, 6, 1-41. https://doi.org/10.1093/oxfordjournals.aob.a088395

[14] Elhani, S., Martos, V., Rharrabti, Y., Royo, C. and Garcia del Moral, L.F. (2007) Contribution of Main Stem and Tillers to Durum Wheat Grain Yield and Its Components Grown in Mediterranean Environments. Field Crops Research, 103, 25-35. https://doi.org/10.1016/j.fcr.2007.05.008

[15] Hucl, P. and Baker, R.J. (1988) An Evaluation of Common Spring Wheat Germplasm for Tillering. Canadian Journal of Plant Science, 68, 1119-1123. https://doi.org/10.4141/cjps88-133

[16] Klepper, B., Rickman, R.W. and Peterson, C.M. (1982) Quantitative Characterization of Vegetative Development in Small Cereal Grains. Agronomy Journal, 74, 789-792. https://doi.org/10.2134/agronj1982.00021962007400050005x

[17] Friend, D.J. (1965) Tillering and Leaf Production in Wheat as Affected by Temperature and Light Intensity. Canadian Journal of Botany, 43, 1063-1076. https://doi.org/10.1139/b65-123

[18] Auld, B.A., Kemp, D.R. and Medd, R.W. (1983) The Influence of Spatial Arrangement on Grain Yield of Wheat. Australian Journal of Agricultural Research, 34, 99-108. https://doi.org/10.1071/AR9830099

[19] Carr, P.M., Horsley, R.D. and Poland, W.W. (2003) Tillage and Seeding Rate Effects on Wheat Cultivars: II. Yield Components. Crop Science, 43, 210-218. https://doi.org/10.2135/cropsci2003.2100

[20] Zadoks, J.C., Chang, T.T. and Konzak, C.F. (1974) A Decimal Code for the Growth Stages of Cereals. Weed Research, 14, 415-421. https://doi.org/10.1111/j.1365-3180.1974.tb01084.x

[21] Hucl, P. (1986) The Effects of Genotype and Environment on Tillering Patterns in Spring Wheat. PhD Dissertation, University of Saskatchewan, Saskatoon.

[22] Ransom, J., Green, A., Simsek, S., Friskop, A., Breiland, M., Friesen, T., et al. (2017) North Dakota Hard Red Spring Wheat Variety Trial Results and Selection Guide. North Dakota State University Extension, Fargo, A574-17.

[23] Carmer, S.G., Nyquist, W.E. and Walker, W.M. (1989) Least Significant Differences from Combined Analyses of Experiments with Two- or Three-Factor Treatment Designs. Agronomy Journal, 81, 665-672. https://doi.org/10.2134/agronj1989.00021962008100040021x

[24] Laundre, J.W. and Reynolds, T.D. (1993) Effects of Soil Structure on Burrow Characteristics of Five Small Mammal Species. The Great Basin Naturalist, 53, 358-366.

[25] Ellsworth, J.W., Jolley, V.D., Nuland, D.S. and Blaylock, A.D. (1998) Use of Hydrogen Release or a Combination of Hydrogen Release and Iron Reduction for Selecting Iron-Efficient Dry Bean and Soybean Cultivars. Journal of Plant Nutrition, 21, 2639-2651. https://doi.org/10.1080/01904169809365594

[26] Rahman, M.R., Shi, Z.H. and Chongfa, C. (2009) Soil Erosion Hazard Evaluation: An Integrated Use of Remote Sensing, GIS and Statistical Approaches with Biophysical Parameters Towards Management Strategies. Ecological Modelling, 220, 1724-1734. https://doi.org/10.1016/j.ecolmodel.2009.04.004 
[27] Clark-Carter, D. (2014) Z Scores. Wiley StatsRef: Statistics Reference, Online. https://doi.org/10.1002/9781118445112.stat06236

[28] Joseph, K.D., Alley, M.M., Brann, D.E. and Gravelle, W.D. (1985) Row Spacing and Seeding Rate Effects on Yield and Yield Components of Soft Red Winter Wheat. Agronomy Journal, 77, 211-214. https://doi.org/10.2134/agronj1985.00021962007700020009x

[29] Puckridge, D. and Donald, C. (1967) Competition among Wheat Plants Sown at a Wide Range of Densities. Australian Journal of Agricultural Research, 18, 193-211. https://doi.org/10.1071/AR9670193

[30] Medd, R.W., Auld, B.A., Kemp, D.R. and Murison, R.D. (1985) The Influence of Wheat Density and Spatial Arrangement on Annual Ryegrass Competition. Australian Journal of Agricultural Research, 36, 361-371.

https://doi.org/10.1071/AR9850361

[31] Simmons, S.R., Rasmusson, D.C. and Wiersma, J.V. (1982) Tillering in Barley: Genotype, Row Spacing, and Seeding Rate Effects. Crop Science, 22, 801-805. https://doi.org/10.2135/cropsci1982.0011183X002200040024x

[32] Goldberg, D.E. (1990) Components of Resource Competition in Plant Communities. In: Grace, J.B. and Tilman, D., Eds., Perspectives of Plant Competition, Academic Press, Cambridge, 27-49.

https://doi.org/10.1016/B978-0-12-294452-9.50007-2

[33] Schenk, H.J., Callaway, R.M. and Mahall, B.E. (1999) Spatial Root Segregation: Are Plants Territorial? Advances in Ecological Research, 28, 145-180. https://doi.org/10.1016/S0065-2504(08)60032-X

[34] Kramer, C.Y. (1956) Extension of Multiple Range Tests to Group Means with Unequal Numbers of Replications. Biometrics, 12, 307-310. https://doi.org/10.2307/3001469

[35] Kirby, E.J.M. (1967) The Effect of Plant Density upon the Growth and Yield of Barley. Journal of Agricultural Science, Cambridge, 68, 317-324. https://doi.org/10.1017/S0021859600012806

[36] Kirby, E.J.M. and Jones, H.G. (1977) The Relations between the Main Shoots and Tillers in Barley Plants. Journal of Agricultural Science, Cambridge, 88, 381-389. https://doi.org/10.1017/S0021859600034870

[37] Gonzalez, F.G., Slafer, G.A. and Miralles, D.J. (2005) Pre-Anthesis Development and Number of Fertile Florets in Wheat as Affected by Photoperiod Sensitivity Genes Ppd-D1 and Ppd-B1. Euphytica, 146, 253-269.

https://doi.org/10.1007/s10681-005-9021-3

[38] Borras-Gelonch, G., Rebetzke, G.J., Richards, R.A. and Romagosa, I. (2012) Genetic Control of Duration of Pre-Anthesis Phases in Wheat and Relationships to Leaf Appearance, Tillering, and Dry Matter Accumulation. Journal of Experimental Botany, 63, 69-89. https://doi.org/10.1093/jxb/err230

[39] Eagles, H.A., Cane, K., Trevaskis, B., Vallance, N., Eastwood, R.F., Gororo, N.N., et al. (2014) Ppd1, Vrn1, ALMT1 and Rht Genes and Their Effects on Grain Yield in Lower Rainfall Environments in Southern Australia. Crop and Pasture Science, 65, 159-170. https://doi.org/10.1071/CP13374

[40] Addisu, M., Snape, J.W., Simmonds, J.R. and Gooding, M.J. (2010) Effects of Reduced Height (Rht) and Photoperiod Insensitivity (Ppd) Alleles on Yield of Wheat in Contrasting Production Systems. Euphytica, 172, 169-181.

https://doi.org/10.1007/s10681-009-0025-2 